\title{
Institutions as Game Theory Outcomes: Towards a Cognitive-Experimental Inquiry
}

\begin{abstract}
Angela Ambrosino
Iniversity of Caster'n Piedmont, Itial!

This paper investigates two different approaches to the analysis of institutions using game theory and discusses their methodological and theoretical implications for further research. Starting from von Neumann and Morgenstern's theory, we investigate, how Schotter and Schelling's approaches to the analysis of economic institutions contribute to develop a proper cognitive method to investigate institutions as the unplanned outcome of self- interested individual behavior? While the game theory model developed by Schotter does not allow to encompass the complexity of decision-making processes leading to the emergence of institutions, Schelling's empirical approach contributes to the cognitive inquiry into economic institutions and it opens the way to an interdisciplinary research method in which pure theory, empirical research and insight coming from different research fields work together. Starting form Schelling's work it is possible to draw the progress achieved by the cognitive economics of institutions and to suggest the need of further experimental and empirical research to better understand the cognitive dynamics that shape human behavior and influence the emergence of economic institutions.

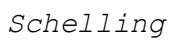

From its first applications in economics, the popularity of game theory has risen and fallen in almost cyclical fashion. The first edition of Von Neumann and Morgenstern's book The Theory of Game and Economic Behavior (1944) aroused the initial excitement. By the late 1950s game theory has been applied in many areas of economic research with varying degrees of success, from oligopoly and price formation processes (Shubik, 1959; Gilles, 1959) to bargaining problems, resource allocation issues and the analysis of social institutions.

At the beginning of the 1970s, authors like Shubik (1971-72) and Hurwicz (1973, 1975)

Manuscript received April 03, 2013; revised May 15, 2013; accepted June 05, 2013.

Corresponding author Email: angela.ambrosino@unito.it focused on the role of social institutions and investigated their impact on economic processes. In this literature, institutions are presented as fixed settings in which the rules of conduct that agents can follow in playing the game are well defined. On the basis of this approach, game theory has been applied to the study of individual behavior in different institutional settings, and it enables economists to analyze the comparative properties of alternative institutions.

However, this tool has also been applied to investigate the emergence of institutional arrangements in a given physical situation or game. In such contexts, social institutions are not part of the rules of the game but are the outcomes of player' $s$ interactions (Ambrosino, 2006) 
International Journal of Management, Economics and Social Sciences

The concept of institutions corresponding to this approach is consistent with Menger' $s$ (1883) and Hayek' s (1962, 1967b, 1988a) theories, that considered institutions to be the unplanned outcomes of social interactions taking place among self-interested economic agents. From this point of view, institutions are the framework in that individuals are able to coordinate their behavior. Moreover, Hayek's theory of the emergence of institutions is closely connected with his theory of mind; the sensory order and the spontaneous order of society are strictly and reciprocally linked (Rizzello, 1997; Caldwell, 2003; Ambrosino, 2006).

Institutions as outcomes of social interaction were one of the economic issues that Von Neumann and Morgenstern had in mind when they began their analysis (Schotter and Schwodiauer, 1980). They suggested that theory should start by describing agents in a "state of nature" from which the theory will predict what standard of behavior will evolve. Institutions (called "standards of behavior" ) emerge as the set of possible equilibrium outcomes of a game of strategy.

After von Neuman and Morgenstern, the inquiry on the emergence of institutional arrangements has been developed in two main directions. On the one hand there is Schotter' $s$ research line, which applies formal game theory models to analyze the emergence of institutions. On the other hand Schelling' s theoretical and empirical research approach investigates the emergence of social rules of behavior. Both these approaches are consistent with Hayek's definition of institutions as the unplanned results of human interaction.

This paper argues that the different research methods applied as well as the different way in that the two authors acknowledge von Neumann and Morgestern's idea of coalition, bring Schotter and Schelling to different explanations of the institutions emergence processes. Moreover, it will be argued that better chances to develop such kind of inquiry will be offered by an interdisciplinary approach (cognitiveexperimental) in which pure theory, empirical research and insight coming from different research fields work together.

This paper is organized into five sections. Section I describes Von Neumann and Morgenstern's main contribution to game theoretical inquiry into social institutions. Section II deals with Schotter' S analysis. Section III points out some distinctive features of Schelling' s approach. Section IV discusses similarities and differences between Schotter' $s$ and Schelling's approaches and investigates how their theories fit with Hayek's theory of institutions. Section $V$ makes some concluding remarks on the promising insights into the institution-creation process afforded by developing Schelling' s research method.

Von Neumann and Morgenstern's Theory of Games and the Emergence of Economic Institutions

Von Neumann and Morgenstern's Theory of Games and Economic Behavior was intended to develop a theory of individual behavior "based on a careful analysis of the ordinary every day 


\section{Ambrosino}

interpretation of economic facts" (von Neumann and Morgenstern, 1944: 7).

Nevertheless, the institutional question almost naturally arises from von Neumann and Morgenstern's work (Hurwicz, 1945; Schotter, 1992) ${ }^{1}$. In fact, because the theory of games with more than two players makes it possible to define the set of mutually exclusive social behaviors by introducing the concept of coalition, it can be considered a tool with which to outline what institutional arrangements - or, in the authors' words, what " orders of society" - may emerge from a given social situation.

This paper considers two main aspects of von Neumann and Morgenstern's theory. First, the emergence of coalitions in $n$-person games and the concept of solution as a set of imputations. Second, the implications of admitting indeterminacy into $n$-player games.

When using game theory to investigate the emergence of institutions, it is important to focus on three or $n$-person games. Three-person games do not correspond to any particular economic problem, but they allow description of the multiplicity distinctive of human relations. These are the interactions in which coalitions can be profitably formed (von Neumann and Morgenstern, 1944).

The simplest constant-sum game which admits to coalition formation has three participants (von Neumann and Morgenstern, 1944). Games of this kind imply that any two players can combine. While any possible combination is in process, each of the players must bear in mind that his likely partner may leave the coalition and join the third participant (von Neumann and Morgenstern, 1944). What a player can obtain from a certain coalition depends on both the rules of the game and the other feasible coalitions. Even, if the rules of the game are inviolable, players may improve an alliance by paying a compensation whose amount depends on what each player can get from the other possible alternative coalitions (von Neumann and Morgenstern, 1944).

A coalition in a zero-sum game implies that the two allies get exactly what the excluded party loses. The purpose of the theory is not to predict which coalition will form. Rather, the theory points out that it would be irrational if no coalition was formed. A consistent theory of three-person zero-sum games will result from looking for solutions that are not single imputations, but rather a system of imputations (von Neumann and Morgenstern, 1944: 36), where an imputation is a given distribution of gains among the players. A set of imputations is a solution if each imputation included in the set is not dominated by the others and every imputation in the set dominates some solutions outside the set.

Hence a solution is not defined with the attributes of existence and uniqueness; rather, it is defined a property of the set that characterizes all possible solutions.

When the concept of solution has been described, the analogy between institutions or standards of behavior and the described set of imputations arises.

Von Neumann and Morgenstern suggest that

1 See Morgenstern \& Schwödiauer (1976). 
International Journal of Management, Economics and Social Sciences

the set of imputations $S$ which we are considering corresponds to "standard of behavior" (von Neumann and Morgenstern, 1944: 41) connected with a social organization. Given a particular social context, individuals are able to adjust themselves, according to traditions and experience, to that context. To do so, they set up a variety of alternatives " which will probably all express some general principles but nevertheless differ among themselves in many particular respects" (von Neumann and Morgenstern, 1944: 41). In terms of social organizations, the concept of solution that they develop explains the emergence of accepted standards of behavior. Solutions as described above, in fact, both have the inner stability that the establishment of social institutions requires and allow for a multiplicity of solutions.

The inner stability of a solution as a set of imputations is expressed by the described peculiar property of imputations.

If the set of imputations can be considered as a standard of behavior, then it has the properties of the solution state: no inner contradiction and any non-conforming behavior must be discredited.

The second main aspect of von Neumann and Morgenstern' $s$ theory is the importance that it gives to indeterminacy.

Their concept of solution does not imply uniqueness. Rather, von Neumann and Morgenstern' $s$ theory admits to a multiplicity of solutions, and it allows for certain degrees of indeterminacy. Indeterminacy and inner stability are not contradictory features.
There is indeterminacy because many different solutions or standards of behavior may emerge from given rules of the game or social contexts. Yet each one of them will have the property of a solution and hence will be characterized by inner stability.

Indeterminacy is not a weakness in von Neumann and Morgenstern's theory. Morgenstern states that indeterminacy is not something to run from but rather to embrace. The world is uncertain and social situations are interesting only because they contain indeterminacies (Schotter, 1992: 107). In the words of Shubik, Von Neumann was even more committed than Morgenstern to the idea of a solution as a set of imputations (Shubik, 1992). Von Neumann and Morgenstern's concept of institution seems consistent with Menger' s theory and with some main aspects of Hayek' s. This theory implicitly claims that institutions may be the unplanned outcomes of social interaction and that they are characterized by a high level of indeterminacy and by inner stability.

\section{Schotter' s Theory of Social Institutions: A Formal Approach for an Evolutionary Theory}

Between the end of the 1970s and the beginning of the 1980s, Schotter applied game theory to develop his theory of institutions (Berman and Schotter, 1979, 1980; Schotter, 1981). Schotter received his training in game theory under the supervision of one of its founders i.e. Oskar Morgenstern. He considers institutions to be properties of the equilibrium of games, and not properties of the game description (Schotter, 1981). 


\section{Ambrosino}

Schotter (1981: 1) examines the nature, evolution and function of social and economic institutions. His purpose is to achieve a positive theory able to describe the type of institutional arrangements that can evolve from a given situation $^{2}$.

Schotter's theory is intended to be a first step in liberating economics from its fixation with competitive markets as all-encompassing institutional frameworks (Schotter, 1981: 1) ${ }^{3}$. Schotter takes von Neumann and Morgenstern' s static analysis a step forward. He considers the institutional issue as an evolutionary one. The analysis of institutions must bear in mind that agents have finite lives, and that their successors inherit a variety of social rules, conventions, institutions and norms that enable the easier coordination of social and economic activities. Hence Schotter calls his game theoretical approach "evolutionary" 4 rather than "dynamic" 5 .

This choice is strictly correlated to the way in which Schotter interprets the concept and role of institutions. He refers to Menger's " organic" theory of institutions, which seeks to explain how institutions - that enable the coordination of social interactions and are necessary for common welfare - arise spontaneously from the selfinterested and selfish interactions of economic agents. Furthermore, Schotter's inquiry is

2 Contrary to Hurwicz (1973, 1975).

3 Schotter recalls Morgenstern (1941,1963, 1972).

4 Sudgen(1986); Young (1991, 1993), Milgrom, North, and Weingast (1990); Greif (1989, 1994); Blowes (2000); Aoki (2001).

5 Evolutionary game thoery originated in biology Lewontin (1961); Maynard Smith (1972); Maynard Smith's work was followed by Axelrod (1984). enriched by Hayek' s theory (1945) that concerns itself with the unplanned or unconscious interaction of social agents in order to investigate the spontaneous or unintended social institutions they create (Schotter, 1981). Schotter (1981: 21) believes that Hayek's types of problems demand a theoretical explanation that can be answered through the use of what we are calling a "state of nature method" 6 .

In embracing Hayek' s theory, Schotter neither mentions nor analyzes the role of individual cognitive processes in determining the routine of behavior that the Viennese economist considered crucial in the emergence of institutions (Rizzello, 1997; Rizzello and Turvani, 2000, 2001; Ambrosino, 2006).

The central thesis of Schotter' $s$ book is that institutions emerge in response to a set of recurrent problems. He states that no economic theory of institution creation can be deterministic, nor can it give unique predictions of the exact institutional form that will emerge. As von Neumann and Morgenstern describe that all the social interactions of interest may lead to many possible equilibrium solutions. Schotter argues that his theory is able to eliminate this indeterminacy and predict which equilibrium social institution will actually be settled upon ${ }^{7}$. By applying an evolutionary game theory approach, he supersedes von Neumann and Morgenstern's

6 In Hayek the evolution of institutions is a cultural process (Hayek, 1988, Caldewell, 2004)

7 The non-cooperative part of the book exludes the concept of indeterminacy. Societies in the real world select one mode of bhevior to solve recurrent problems, so that a deterministic thory is possible. Indeterminacy is important in cross cultural analysis (Schotter, 2007). 
International Journal of Management, Economics and Social Sciences

idea of the desirability of indeterminacy. Schotter had in mind a theory based on repeated games. In this games it is assumed that when a player dies he is replaced by his offspring and that each player can transfer his accumulated knowledge to his children. This means that each new generation will be informed of the particular institution (payoff) chosen by their parents. It is likely that this knowledge will affect the solution in the next period game. In Schotter' $s$ words " arbitrary arrangements may become fossilized in the economy and these arrangements become parameters or permanent features of the society as it continues to evolve. Consequently, many generations later, a payoff/institution pair may exist that govern this game or situation, without being obvious why that particular pair is chosen" (Schotter, 1981: 14). It becomes clear that a stable institutional arrangement depends closely on the history of how the game has been played.

In Schotter's model, indeterminacy is resolved by modeling the emergence of institutions as a stochastic process in which the equilibrium determines the state in which the expectations of all the players are such that they all expect the others to behave in a particular manner with probability equal to one; and that is exactly what they will see happen (Schotter, 1981).

Before setting out his mathematical model, Schotter describes four basic problems representing the main types of social-interaction difficulties for which economic institutions may arise as solutions: coordination problems, problems of prisoners' dilemma type, inequality-preserving problems and some cases of the cooperative game type. Basically, Schotter argues that the interactions from which institutions arise organically, as the result of individual action and not of collective behavior, must be described with games played noncooperatively or without communication among players. Indeed, in these kinds of games, rules of behavior emerge as the outcome of selfinterested human action, not by human design. Otherwise, there are other types of interaction in which institutions are created by the explicit human design of a social planner or result from an explicit social bargaining process. The case of institutions settled by a social planner is not interesting from Schotter's point of view ${ }^{8}$. In fact, again referring to Hayek (1945), he emphasizes that this case can easily be described by maximizing some objective function of the social planner. Moreover, even assuming that the problem of the emergence of institutions could be solved straightforwardly, it would be only a partial explanation of a wider problem

Also all those social states in which agent' $s$ interactions can be described as bargaining processes are of relatively no interest. These cases need a theory of bargaining to describe the process through which agents can explicitly agree on the institutions they want to be governed by .

Schotter admits the existence of social interaction equivalent to cooperative $n$-person games from which institutions emerge organically. But these cases are residual in his inquiry. He refers to problems of prisoners' dilemma type, and he does not analyze either

8 Contrary to Shubik and Shaplley (1977) and Hurwicz (1973). 


\section{Ambrosino}

inequality-preserving problems (which belong to the coordination problems) or cooperative problems. The only case he quoted was Nozick' s example on the emergence of the state from a state-of-nature. Schotter focuses on Nozick' $s$ theory of the rise of the minimal state (Nozick, 1975) only to stress the merits of the state-of-nature approach. Yet Schotter underlines that the cooperative problem settled by Nozick shows interesting aspect in an institutional perspective, nevertheless, in his inquiry he does not consider cooperative $n$ person games further. This particular methodological choice is explained by Schotter' $s$ belief that non-cooperative games are those that best describe the unplanned interactions among players from which institutions emerge. Furthermore, far from considering cooperative game theory as an unprofitable approach to institution creation processes, Schotter chooses instead to focus on noncooperative games because the manner in which cooperative game theory has been developed since von Neumann and Morgenstern has proved disappointing. Its failure has been due to the misplaced emphasis that has characterized the application of this theory to the problem of general equilibrium. Analysis of this kind concentrates wholly on the core solution concept, which explains the evolution of competitive markets but does not explain the evolution of any other institution. Schotter' $s$ theory disregards the important opportunities offered by cooperative game theory to move beyond the neoclassical model by allowing agents unlimited strategic freedom within the rules of the game. This freedom takes the form of processes of coalition-formation among players and is an important theoretical concept with which to explain the evolution of social institutions as endogenous processes (Schotter, 1981).

After this preliminary discussion Schotter develops his formal theory of institutions. This theory is divided into two parts (the first presents the model in the two-person prisoner' $s$ dilemma case, the second generalizes the discussion), and it is based on analysis of the super-games equilibrium convention. The aim is to develop a formal evolutionary game theory of institutions in which successive generations of players are involved in solving the same recurrent problem. Schotter technically frames the problem as a super-game (constituent game), that is obtained by infinitely iterating a static game. In this supergame, the players are aware that they will interact with each other for an infinite number of time periods, and that they must evaluate this fact in deciding how to behave. The players must recognize " the fact that the actions they take today are bound to influence the expectations that the other player will have about them in the future and hence the other player's future behavior" (Schotter, 1981: 56). As time passes, the players tacitly learn what kind of behavior they can expect from the others. If this behavior is an equilibrium and becomes a convention among the players, it prescribes how agents should behave in each later interaction of the same type. In the two-person recurrent prisoner's dilemma game, Schotter describes how it is possible to predict the exact equilibrium convention by representing it as a stochastic event. Generalizing the model to analyze $n$-person games, Schotter 
International Journal of Management, Economics and Social Sciences

formally demonstrates that, through a Markovian diffusion process, it is possible to determine how long does it take to a given social group to establish a particular social convention as a guide for its behavior which enables agents to solve the particular recurrent economic problem that they face. Schotter' s model of institutions creation fulfils the aim of his inquiry because it both investigates institutions as organically generated and makes it possible to eliminate indeterminacy in predicting which particular institutions will emerge.

However, the stringent assumptions (players' rational behavior, problems of non-cooperative prisoner's dilemma type) necessary to achieve this goal force Schotter to almost entirely omit those aspects of the institution-creation processes related to individual cognition (learning processes, routine development), although he acknowledges their importance.

As in Hayek (1945), institutions perform an essential informative function. They " codify memory", so that the social interactions described by the game of imperfect recall can be transformed into games of institution-assigned perfect recall (Schotter, 1981: 109). Moreover, the informative function of institutions is strictly linked to the history of the game. That suggests the importance of both the individual cognitive process in classifying information and of the cultural context in assigning a particular meaning to information.

Schotter's idea of the emergence of institutions as an endogenous process implies a learning process that enables player to foresee each other's behavior. Learning is reduced in the formal model to a stochastic process. In the last chapter of the book, however, Schotter questions the relevance of the biogenetic individual structure to institutions-creation dynamics. His main contention is that standards of behavior emerge to help agents solve recurrent economic problems. If the social group adheres to them, then those standards of behavior form the basis for Schotter's definition of institutions. The question Schotter raises is very simply stated. There could be pre-existing innate biases or cognitive processes that make a certain solution to a recurrent interaction problem more natural than others and that thus influence the probability that exactly that solution will arise (Schotter, 1981).

He suggests two possible explanations for the importance of such individual predispositions. First, Laughlin and d' Aquili (1974) suggest that there may be standards of behavior more consistent with basic biogenetic structures which exist in the human mind and that have possibly evolved because social coordination is essential for successful social existence and reproduction, and these patterns or structures facilitate such coordination and hence increase the fitness of human beings possessing them (Schotter, 1981).

Secondly, Schelling's The Strategy of Conflict (1960) suggests that the solution to the interdependent decision problems, based on the concept of salience, introduces the role of cultural background in coordinating individual behavior (Schotter, 1981).

Schotter' $s$ awareness of the complexity of the institutions-creation processes is even more evident in his later inquiries. After the 1980s his 


\section{Ambrosino}

interest gradually moved from pure theory to an experimental approach (Schotter, 2007).

In the last ten years his research interest has returned to institutions. His aim is now to investigate experimentally how each generation of agents can influence its successor' $s$ behavior so that social conventions appear to emerge over time and are passed from generation to generation. Social learning plays a crucial role in this process (Merlo and Schotter, 1999, 2003; Schotter, 2003; Schotter and Sopher, 2003).

Schotter's experimental research on the learning processes that give rise to social conventions seems consistent with his previous work. These empirical studies better encompass the complexity of the decision-making and institution-creation processes, and they are more consistent with Schotter' s (1981) observations on Schelling' s empirical inquiry.

\section{Schelling's Contribution: An Empirical Approach to Complex Interaction Processes}

In the years immediately following von Neumann and Morgenstern's book (1944), Thomas Schelling became interested in game theory. From the outset, he has taken a quite distinctive approach to game theory ${ }^{9}$. Fascinated by the complexity of social issues, Schelling finds game theory a useful tool with which to investigate that complexity and to understand reality (Dodge, 2006). Throughout his career, his research approach has been characterized by a combination of empirical and theoretical inquiries (Schelling, 1960, 1984, 2006).

Schelling's work is not directly aimed at investigating the role and the rise of institutions. However, his entire inquiry is based on the study of decision processes characterized by the interdependence of player' $s$ choices (Schelling, 1960, 1961, 1978, 2006). All the problems of interest to economics and social science involve interaction processes in which agents must understand each other. They must identify standards of behavior that make each player' $s$ action predictable by the others; they must jointly develop shared behavior regularities, or conventions.

The solution of economic and social problems requires complex interaction processes. The institutional issue is almost implicitly involved in Schelling' $s$ inquiries. The processes of interaction described by Schelling suggest that there may be interesting links between them and those interactions that lead to the emergence of institutions outlined in Hayek's theory (Ambrosino, 2006).

Schelling $(1960,1978)$ applies what he refers to as a less restrictive and formalized definition of game theory to investigate individual interaction processes.

Game theory - defined as the study of how rational agents choose when the best choice between two or more possible alternatives depends on the choices that others have to make - is the framework in which many types of situations can be analyzed (Schelling, 1960, 2006). Schelling suggests that such a framework may be even more helpful if two assumptions connoting the game theory approach are considered as starting point, first, players are

\footnotetext{
9 Dodge (2006); Schelling (2005).
} 
International Journal of Management, Economics and Social Sciences

perfectly rational, and second, people only care about outcomes. Methods and models must be adjusted when their assumptions are not valid to explain the complexity of particular cases (Schelling, in Dodge, 2006; Ambrosino and Biancone, 2013).

Schelling does not reject the concepts of indeterminacy and coalitions developed by von Neumann and Morgenstern.

The Strategy of Conflict (1960) is an inquiry into the strategy of international affairs that leads to a systematic analysis of interdependent decisions processes. Schelling's main contention is that almost all the circumstances in which agents interact are characterized by different degrees of conflict. Pure conflict and pure collaborative interactions are extreme cases, but almost all interactions among players involve some level of both conflict and common interest $^{10}$. This means that when dealing with an interdependent decision problem, each player must consider that his choice is dependent on the other player' s action.

Schelling' $s$ emphasis on the simultaneous existence of different degrees of conflict and cooperation suggests that his conception of interaction is quite similar to von Neumann and Morgenstern' s. These authors do not distinguish between cooperative and non-cooperative games. Rather, they argue that zero-sum games are the only cases of real conflict, while every other kind of game comprises some level of cooperation and may allow coalitions to form (von Neumann and Morgenstern, 1944).

10

Harsanyi (1964)
In Schelling' $s$ analysis, therefore, social interactions are interpreted as mutualdependence games in which adversaries must tacitly or explicitly interpret each other' $s$ behavior. Schelling argues that such games must be investigated by re-orienting game theory. Neither simple cooperative game theory nor pure non-cooperative games models are able entirely to handle the complexity of the coexistence of conflict and common interest (Schelling, 1958). What is needed is a theory that identifies the perceptual and suggestive element involved in the process producing the player's mutually consistent expectations, and in which the structural elements of the strategic interaction are investigated (Schelling, 1960 - . 84). Game theory, which began as a theory of protection against interaction, becomes in Schelling' $s$ conceptualization of mixed-motive games the theory of strategic interaction (Bernard, 1964: 444).

Schelling (1960), far from considering the results obtained by the theory of the zero-sum game as useless, developed his theory of bargaining games or mixed-motive games ${ }^{11}$. These games better represent those interaction situations that, though characterized by some degree of conflict, entail mutual dependence as a feature of the game, and in which some kind of, tacit or explicit, collaboration or mutual accommodation is needed to avoid mutual disaster (Schelling, 1960).

Schelling (1960) investigates both explicit and tacit bargaining. He starts from interdependent decision situations in which communication is 


\section{Ambrosino}

denied. These situations are simply described by standard game theory as non-cooperative games. He observes that even if players are not allowed to communicate with each other, they try to think vicariously ${ }^{12}$. The players develop composite expectations, and they have to perceive mutual expectations intuitively. Mixed motive games can better explain the complexity of such interactions.

\begin{tabular}{|c|c|c|}
\hline & I & II \\
\hline $\boldsymbol{I}$ & 10,10 & 0,0 \\
\hline $\boldsymbol{i i}$ & 0,0 & 10,10 \\
\hline
\end{tabular}

Figure.1 Schelling (1960: 342) this is a coordination game. It is an example of a strategic interaction in that two equilibria are possible, none of that is preferred by agents. Schelling argues that in real life agents are able to solve problems of this kind successfully. Agents coordinate focusing on some clues of context that make one particular outcome to be the solution. The relevance of such clues is what makes the selected solution to become a proper rule of behaviour in repeated interactions.

When players perform mixed motive games in the real world, they are able to solve the problem. Moreover, they certainly do conspicuously better that any chance methods would have permitted (Schelling, 1960). This means that expectations can be tacitly and mutually coordinated to achieve a solution that does not depend on the logical structure of the game, but rather is determined by something that is fairly arbitrary (Schelling, 1960). Most tacit bargaining situations provide some clue for coordinating behavior, some focal point for each person's expectation of what the other expects him to expect to be expected to do (Schelling, 1960). On being

11 Schelling, (1958).

12 Schelling's vicarious thinking is not of the "what would I do if I ware he?" kind. Players reason together..They predict what the other player will do and choose what to do themselves. Players are aware that they all are reasoning in the same way toward a common solution (Sudgen \& Zamorrón 2006:9). mutually recognized as the possible solution, this focal point is able to become the key to the problem. It does not simply depend on logic; it may depend on imagination, analogy, precedent, accidental arrangement, symmetry, the aesthetic or geometric configuration of the problem, casuistic reasoning, and who the parties are and what they know about each other ${ }^{13}$ (Schelling, 1960). The focal point enables the coordination of expectations because it embodies characteristics of prominence with respect to time, place and the players involved in the game, and of uniqueness, which prevent it from being ambiguous.

Schelling's discussion of the appearance of a focal point to solve tacit pure-coordination problems is even more useful when it highlights the institutional nature of focal point. In purecoordination games, the players have convergent interests. Nevertheless, in these games too, a player cannot choose an action without regard to the dependence of the outcome on the other player's choice. The solution of these interactions depends on the player's ability mutually to perceive a focal point. Schelling argues that it is exactly this process that accounts for the rise and the stability of institutions. The force of many rules of etiquette and social restraint, including some that have been divested of their relevance or authority, seems to depend on their having become "solutions" to a coordination game: everyone expects everyone to expect everyone to expect observance, so that non-observance carries the pain of conspicuousness (Schelling, 1960). The 
International Journal of Management, Economics and Social Sciences

institutional nature of the focal point is also due to its tendency to become a stable solution for recurrent interaction problems. In fact, even if Schelling refers to one-shot games, he implicitly suggests that most real-world games are played repeatedly (Leeson, Coyne and Boettke, 2006). Moreover, the focal point arises organically from unplanned individual interaction and, like social institutions, it shares the scope and the nature of what Hayek defines as institutions (Ambrosino, 2006). In fact, in mixed-motives games each player pursues his own interest, but the solution of the interaction process is able to become a stable rule if the coordination problem is repeated $^{14}$. Shelling argues that the concept of role, which in sociology refers to the rights, obligations, and expected behavior patterns associated with a particular social status, explicitly involves both the expectations that others have about our behavior and the expectations we have about how others will behave. This allows him to interpret this concept as the stable "convergent expectations" solution of a coordination game. A particular role evolves in society, like a focal point does in a coordination game, because it is the only possible one that players in the specific circumstances can identify by a tacit interaction process (Schelling, 1960).

The main feature of the focal point makes it evident that indeterminacy is an important aspect of the theory of interdependent decisions. Focal

13 Sudgen and Zamarron (2006).

14 Players in Schelling act according to their own interest but they are not necessarily selfish. This difference between self-interest and selfishness is also relevant in Hayek's theory (Hayek , 1967). points, like institutions, are not predictable. Every mixed-motive game may have more than one solution, each of them preferable for the players to no solution at all. A focal point arises where there is a multitude of equilibria. Which solution, which focal point, will be chosen in a given situation depends on the specific features of the game and of the players involved in it.

The analysis of tacit bargaining problems provides Schelling with the analytical model necessary also to comprehend the more general case of explicit interaction problems. This is firstly, because the psychic process of mutual perception, that has an important part in tacit cases, plays the important role of expectations coordination also in the analysis of explicit bargaining, and secondly because most explicit game situations also involve a tacit dynamic process of mutual accommodation that makes them different from pure communication culminating in crystallized agreement (Schelling, 1960).

Also when communication is allowed, the outcome of a bargaining process depends on the specific situation, on how the problem is formulated, on the analogies and precedents it calls to mind and on the data available to solve the question. Schelling argues that also explicit mixed-motives games require some coordination of the participant' $s$ expectations. He suggests that tacit and explicit bargaining are not separate concepts. Games have different gradations of communication, from tacit interaction to various degrees of communication incompleteness. In each case, the participants must pay attention to the "communication" comprised in the 


\section{Ambrosino}

inanimate details of the situation (Schelling, 1960). This does not mean that the same interaction problem in explicit and tacit versions will have exactly the same solution. Rather, it means that the focal point may be very different when communication is allowed, for what may be important in tacit bargaining because it has the features of prominence and uniqueness may not be as important in explicit interaction (Schelling, 1960).

The institutional nature of the focal point in not strictly tacit social interaction stems from the same consideration that Schelling makes when analyzing coordination problems. Moreover, the existence of precedents has a great influence which often exceeds the logical importance of other solutions (Schelling, 1960). This indicates that also in explicit bargaining the focal point which emerges as the solution to a specific problem is able to stabilize itself into a consolidated rule.

There is one more reason for focusing on Schelling' $s$ arguments on explicit bargaining. These games are of the same kind as those which game theory terms cooperative games. When cooperative games involve more than two players, von Neumann and Morgenstern point out that coalitions among players may arise.

It seems from the previous discussion that Schelling does not exclude coalition formation in either explicit or tacit bargaining.

The theory of focal points refers to the ability of agents to coordinate their expectations with respect to the particular features of the situation. This suggests that if the interaction problem involves more that two players and if clues that the context offers focus the player' $s$ attention on the usefulness of a coalition, that coalition is better also for the excluded player in all those interdependent decision problems in which finding a solution is better than no agreement at all.

Because the dynamics leading players to a particular focal point are even more important in tacit interaction, this indicates that $n$-person tacit games may involve mutual perception processes based on psychological factors which induce players to form coalitions to solve the problem.

Schelling' $s$ model of social interaction introduces psychological factors as the very essence of the problem and describes players as no longer accepting the payoff matrix as fixed (Bernard, 1954). It defines players as trying to change their opponent' $s$ payoff and their tactics. Schelling argues that in so complex a social interaction the object of each player' $s$ strategy is no longer to make the best of the situation but to "manipulate" the opponent to change the situation (Bernard, 1954). Agents will use strategies to form coalitions whenever they can lead them to a solution. The emergence of possible coalitions does not imply that the outcome of the game can be considered predetermined or planned by the agents. Each player' s strategy is aimed at finding a common solution, which is better than no solution at all. What solution emerges from the interaction is a consequence of the dynamics and the features of the game, and of the agent's psychological characteristics.

The ability of players to coordinate their behavior in situations in which their interests are totally or partially opposed, and in which 
International Journal of Management, Economics and Social Sciences

communication is partially permitted, indicates that the existence of focal points enables players to transform a worst situation into a better one in which partial cooperation is possible (Leeson et al., 2006). But it does not mean that it is possible to predict which focal point will be the solution or that the solution will be planned by the players.

The importance and complexity of mutual perception processes, and the difference between self-interest and the unplanned outcome that players actually achieve in their interaction, is well emphasized in Schelling's Micromotives and Macrobehavior (1978). In this book Schelling investigates the relationship between individual' $s$ behavior characteristics and the characteristics of the aggregate (Schelling, 1978). In this case, too, the field of inquiry is the interdependent decision process. Schelling main contention is that many social situations are structured so that individual players, behaving in a self-interested way, may jointly produce an outcome that is collectively less than optimal. In many social interactions, people' s behavior depends on how many are behaving in a particular way (Schelling, 1978). The point is that there is a critical mass level that once reached makes the process selfsustaining. In the case of the rise of social norms from agent' $s$ interaction, it may happen that a particularly institution becomes hard to change even if everyone recognizes that it is inferior to many possible others.

Schelling' s theory of focal point explains both the rise of common solutions to social interaction problems and their tendency to become stable solutions (proper institutions) to repeated interaction problems. Moreover, also the concept of critical mass is important in explaining why the unplanned outcomes of social interaction may be self-reinforcing. In fact, if social institutions are the effects of a process in which the critical mass mechanism works, then it is exactly this mechanism that makes such institutions selfsustaining and self-reinforcing. Both the processes (one generating a focal point, the other suggesting that there are forces compelling toward convergence in social interaction) can be relevant at the same time, even if they may have different effects on the institutions-creation processes. The focal point allows coordination in individual interactions where reaching a solution is better than no agreement at all. It may also play an important role when interaction takes place among a large number of individuals. Schelling (1960) argues that the focal point works in $n-$ person games. The outcome of this interaction is not the one that everyone desires. In this sense, the focal point may be part of the process that makes the critical mass self-sustaining, because in so far as individuals mutually perceive that solution (even if it is the inferior one) as the focal point; they contribute to the self-sustaining process that reinforces the normative nature of that solution. On the other hand, any change in the context or in the mutual perception of the players may lead to rejection of a particular solution as a focal point. This may trigger a change process.

The two concepts of focal point and critical mass in Schelling' $s$ explanation of the institutions-creation process suggest a possible explanation for the emergence of institutions as a dynamic process in which mutual perception 


\section{Ambrosino}

involves logical, psychological and cultural factors.

The way in which the focal point and critical mass work highlights that institution-creation processes are characterized by indeterminacy, and that this cannot be eliminated simply by modeling such processes as stochastic events, as Schotter suggests.

How Schotter' $s$ and Schelling' $s$ Analysis Fit Hayek' s Theory of Institutions Creation?

The previous sections argued that both Schotter's and Schelling's concept of institution are strongly related to the complexity of the processes of social interaction from which social norms and institutions emerge. Both authors underline the relevance on psychological and cognitive determinants in such processes. In that their ideas share some relevant aspects of Hayek' s theory of social institutions.

Hayek's theory of the emergence of institutions from social interaction is closely linked to his theory of the mind (Rizzello, 1997; Caldwell, 2003, 2004; Ambrosino, 2006).

In Hayek (1952), the human mind is the framework in which external stimuli are associated, through neurobiological perception and classification phenomena, with classes of actions. Each action is strictly connected with perception and depends on individual genetic structures and individual past experiences. Individuals are heterogeneous and have idiosyncratic experiences, which are the reason why behavior is not predictable. The result of the cognitive process of organization and classification of external stimuli is termed the sensory order (Hayek, 1952).
Institutions constitute the framework that enables heterogeneous agents to coordinate their behavior in a social context characterized by uncertainty and only partial information (Hayek, 1967).

The spontaneous social order emerging from a cultural evolution process and enabling agents to select the more profitable institutions to coordinate social behavior is the unplanned outcome of social interactions in which individual' $s$ actions are the result of such complex perception and classification processes. Coordination is itself the product of the ability of heterogeneous agents to recognize the action patterns of other individuals by perceiving their own action patterns (Hayek, 1967: 57).

The spontaneous order is in some respects the "effect" of the sensory order. It becomes an endless process composed of two main elements: first, agents mutually perceive and classify their behavior so as to decide their own action; second, a multitude of agents with partial and idiosyncratic knowledge of the context understand how to coordinate (Hayek, 1937, 1945).

Von Neumann and Morgenstern's theory singles out a concept of solution as standard of behavior that shares important features with Menger' $s$ and Hayek's concept of institutions. In particular, von Neumann and Morgenstern's analysis seems to be consistent with some aspects of Hayek' s concepts of institutions that Schotter' s inquiry does not encompass.

von Neumann and Morgenstern's concept of standards of behavior implicitly shares Hayek's definition of institutions as a framework bounding 
International Journal of Management, Economics and Social Sciences

the range of available choices that individuals can make and enabling people to coordinate their behavior (Hayek, 1967).

Moreover, their analysis of the standards of behavior connected with social organizations shows that tradition, experience and social context play an important part in making individuals adjust their behavior. The standards of behavior that enable coordination in social interaction are not only characterized by indeterminacy; they are linked to experience and they may also change. These features of von Neumann and Morgenstern's solution concept recall what Hayek terms spontaneous social order.

This does not signify that von Neumann and Morgenstern's theory entirely supports Hayek' s. Although the aim of game theory is to investigate complex interactions (Neumann and Morgenstern, 1944: 11), it is based on the assumption of the perfect rationality of players. Decision-making is an entirely logical process in which agents maximize their expected utilities and make a probabilistic evaluation of the possible solutions. In von Neumann and Morgenstern, there is no room for the complexity of the cognitive processes that in Hayek' s theory flank the interaction processes leading to institutions creation.

Schotter (1981) explicitly links his inquiry to Hayek' s theory of institution. Yet his formal model of institutions-creation forced him to exclude not only the cognitive foundations of behavior but also some degree of indeterminacy in predicting which institution will emerge.
Schotter's theory encompasses Hayek' s concept of institutions as the outcomes of free self-interested interactions and their essential informative role (Schotter, 1981). He shares Hayek's notions that certain actions become rules of behavior (and then proper institutions) through iterated interactions, and that the emergence of particular institutions is strictly linked with the history of the game (Schotter, 1981). But his stochastic model is based on strict assumptions concerning the player' $s$ perfect rationality and on the non-cooperative nature of the interactions that give rise to institutions. Schotter develops a formal model able to predict which institution will emerge from social interaction. His rejection of von Neumann and Morgenstern's concept of indeterminacy and of their view that social interactions basically involve cooperation prevents his theory from including certain features of Hayek's analysis that he himself pointed out as important.

Although Schotter suggests the importance of individual decision processes in social behavior, he entirely fails to consider the Hayekian sensory order lying beneath the social order.

If the importance of certain biological and cognitive determinants in shaping individual' $s$ behavior is assumed, then different theories are needed to explain institution-creation processes (Schotter, 1981). Schotter explicitly refers to Schelling's The Strategy of Conflict (1960), that provides evidence for the existence of " natural solutions" in coordination problems and explains them as the result of similar forms of cultural training (Schotter, 1981). Furthermore, Schotter argues that in some sense his theory of 


\section{Ambrosino}

institutions is compatible with Schelling' $s$ theory of focal point. In fact, he suggests that "when an institution of my type is selected, in order to be successful, it has to be a focal point" (Schotter, 2007).

Schelling's theory of interdependent decisions corroborates many features of Hayek's theory of institutions.

The focal point is not predictable by a formal or mathematical model. Rather, like Hayek's institutions, it depends on the specific features of the game and on the cultural and cognitive characteristics of the players. ${ }^{15}$ As far as a certain behavior is socially recognized as a focal point, it is able to coordinate social behavior and to constitute the social order. When changes in the environment or in the perceptual abilities of players make them reject this focal point, a new process leading to the emergence of a new behavioral rule will begin.

Schelling does not reject the assumption of the player's perfect rationality. He suggests that rationality is not simply constituted by the cold logical ability to calculate the best choice to make; rather it includes the ability to perceive when the solution of an interaction situation involves psychological or cultural or even more complex aspects of cognition (Schelling, 1960). These psychological features must be included in the analysis of bargaining processes (Ambrosino and Biancone, 2013).

The theory of interdependent decisions addresses the two main problems which, according to Hayek, are crucial in the social interaction process leading to social order: mutual perception of the other' $s$ behavior, and the need for coordinating rules.

\begin{tabular}{|c|c|c|}
\hline & I & II \\
\hline $\boldsymbol{i}$ & 9,9 & 0,0 \\
\hline $\boldsymbol{i i}$ & 0,0 & 10,10 \\
\hline
\end{tabular}

Figure 2, Schelling (1960: 341), this is a coordination game in that apparently the payoff (II, ii) is better than $(i, \quad I)$. Schelling argues that in many real life circumstances this matrix describes an interaction in that players are more interested in obtaining 9 or 10 instead of 0 than in obtaining 10 instead of 9. In this kind of real interactions the outcome of the games depends on some focal point that cannot be determined by mathematical models but that depends on some specific features of the decision problem. This result seems to be coherent with Hayek's idea of social order. In fact, the outcome of this kind of interaction can be not the Pareto efficient payoff but the outcome that agents perceive as the more appropriate to solve the interaction problem. This outcome because it is able to coordinate agent's behaviour can be repeated and can become a proper rule of behavior.

An interdisciplinary approach is important to investigate economic institutions considered the unplanned outcome of social interaction because it allows describing and understanding the peculiarity of decision making processes and of human behavior.

What Schelling argues does not mean that his theory completely fits with Hayek's theory. However, his model of bargaining, because it is empirically founded and not formalized and allows a certain level of cooperation in almost all social interactions, is largely compatible with Hayek's theories.

Schelling's methodological approach releases strictly formal models. This suggests that they make it impossible to include all those features of the game that have an important role in enabling players to reach a common solution (Schelling, 1960). If the cognitive processes in individual decision-making are not the problems Schelling is determined to analyze, the complexity of such problems is something he takes care in developing his work.

15 See Leeson et al., (2006). 
International Journal of Management, Economics and Social Sciences

\section{CONCLUSION}

This paper has investigated different approaches to the analysis of institutions as the outcomes of social interaction. Von Neumann and Morgenstern's inquiry as the same of Schotter's and Schelling's yields important insights into how social interactions give rise to institutions, and they are able to corroborate some aspects of Hayek's theory.

Both Schotter and Schelling consider game theory to be an important tool for the analysis of social institutions as the unplanned outcomes of social interaction. Furthermore, Schelling's more empirical approach proves to be a better fit with Hayek's theory of institutions and the importance within it of his theory of mind.

Particularly the paper suggests that Schotter's methodological choice, aimed at developing an evolutionary mathematical model of institutions, forced him to exclude from his analysis some aspects that he considers, been relevant in the institutions creation processes such as von Neumann and Morgenstern's ideas of indeterminacy and Hayek's role of cognitive determinants.

Schelling' s methodological choice, on the other hand, suggests that Schotter's (1981) difficulties in developing a formal model including the individual cognitive processes considered by Hayek can be overcome by releasing strictly mathematical models, and by moving toward a mixture of "pure" and "applied" research (Schelling, 2006), in which there is room for von Neumann and Morgenstern's idea of indeterminacy.
Testifying to the profound impact of Schelling' $s$ theories and methodological approach on the social sciences, especially on game theory and on experimental economics, is the large number of citations in academic journals and several scientific research projects that have developed his theoretical or experimental inquiries (Colman, 2006; Sudgen and Zamarròn, 2006).

Schelling himself (2006) stresses that the analytical approach that he describes and applies in The Strategy of Conflict, as in his later works, has not yet been completely corroborated by further applications. Most recent works based on his theories have not developed his distinctive research approach. Game theorists have sought to include Schelling' $s$ ideas in the formal refinements of game theory (Gauthier, 1975; Sudgen, 1995; Janssen, 2001), and experimental applications have been conditioned by the need for perfectly controlled conditions in the experimental set up (Metha Starmer and Sugden, 1990, 1994; Radner and Schotter, 1989; Roth, 1985; Roth and Murnighan, 1982). But all these inquiries seem to forget the original purpose of Schelling's methodological choices: "motivation for pure theory came almost exclusively from my preoccupation with (and fascination with) "applied" problems; and the clarification of theoretical ideas were absolutely dependent on an identification of live examples" (Schelling, 1993: 18).

But perhaps something is about to change: the Nobel Prize' $s$ wishes seem to be picked out by Schotter's more recent works in which he experimentally investigates the rise of social 


\section{Ambrosino}

conventions in intergenerational games (Merlo and Schotter, 1999, 2003; Schotter, 2003; Schotter and Sopher, 2003).

Schotter developed his interest in applied research during the 1970s when he undertook his first experimental work (Schotter, 2007). Since then, Schotter has grown increasingly aware that the refinements achieved by pure game theory contribute more to the philosophy of science than to economics. He maintains that economics needs tools with which to test theories and to understand real economic processes. Hence, his experimental research is based on strong theoretical hypotheses and uses the game theory framework to describe social interaction, but its aim is to investigate the processes through which agents make their decisions in social interaction. Schotter' s experimental research therefore seems to accord with Schelling' $s$ methodological choices, and his analysis of the rise of social conventions could represent a step forward in the investigation of institution-creation processes.

Nevertheless, the explanatory importance of a methodological approach that is a mixture of pure and applied theory has not yet been completely acknowledged by the profession. By focusing on the non-cooperative side, game theory has achieved great formal refinement and has become a normative theory of behavior (Aumann, 1985). At the same time, experimental applications of game theory have often adhered to this mathematical refinement rather than considering game theory as simply a reasoning framework. The results arising from both Schelling' $s$ and Schotter's recent works suggest that there is still place to develop an interdisciplinary and experimental inquiry to understand the micro-foundations of institutions which encompasses both the relevance of cognitive determinants and the complexity of social interactions.

\section{REFERENCES}

Ambrosino, A. (2006). Verso una Teoria Cognitiva delle istituzioni Economiche. Unpublished PhD Disseration, Turin, Italy.

Ambrosino A. \& Biancone P.P. (2013). Rationality as a collection of attributes: Theoretical and methodological implication of Schelling' $s$ theory of rational behavior for cognitive economic theory. International Journal of Sociology Study, 1(1): 17-28.

Aoki, M. (2001). Toward a comparative institutional analysis. MIT Press, Cambridge.

Axelrod, R. (1984). The evolution of cooperation. New York: Basic Books.

Aumann, R. (1959). Acceptable points in general cooperative n-person games. In Tucker, A.W. \& Luce, R.D. (Eds.). Contributions to the Theory of Games IV, 287-324. Princeton University Press.

Aumann, R. (1985). What is game theory trying to accomplish?. In Arrow K. \& Honkaphola, S. (Eds.), 28-76. Frontiers in economics. Basil Blackwell, Oxford.

Bernard, J. (1954). The theory of game as a modern sociology of conflict. The American Journal of Sociology, $59,418-431$.

Berman, S. M. \& Schotter, A. (1979). Supergames and diffusion processes: A theory of norm and institution assisted supergames. Discussion papers, 79-01. Starr Centre for Applied Economics, New York University, New York.

Berman, S. M. \& Schotter, A. (1980). When is the Incentive Problem Real? Working Papers 80-20, Starr Center for Applied Economics. New York University, New York.

Blowes S. (2000). Economic institutions and behavior: An evolutionary approach to microeconomic theory, book manuscript.

Caldwell B. (2003). Hayek's Challenge, Chicago: Chicago University Press. 
International Journal of Management, Economics and Social Sciences

Caldwell B. (2004). Hayekian evolution reconsidered: a reply to Hodgson. Cambridge Journal of Economics, 28, 301305.

Colman A. M. (2006). Thomas C. Schelling's psychological decision theory: Introduction to a special issue, Journal of Economic Psychology, 27, 603-608.

Commons J.R. (1934). Institutional Economics, New York: Macmillan.

Dodge R. (2006). The strategist:The life and times of Thomas Schelling. New Hampshire: Hollis Publishing Co.

Friedman J. W. (1977). Oligopoly and the theory of games. Amsterdam: North-Holland Publishing Co.

Gauthier D. (1975). Coordination. Dialogue, 14, 195- 221.

Gilles D. B. (1959). Solution to general non-zero-sum games. In Tucker, A. \& Luce, D. (Eds.). Annals of mathematics studies, contributions to the theory of game: 47-85. Princeton: Princeton University Press:, IV(40): 4785.

Greif A. (1989). Reputation and coalitions in medieval trade:

Evidence from the maghreb traders. Journal of Economic History, 44, 857-882.

Greif A. (1994). Cultural beliefs and the organization of society: A historical and theoretical reflection on collectivist and individualist societies, Journal of Political Economy, 102, 912-50.

Hayek F.A. (1937). Economic and knowledge. Economica, 13, 96-105.

Hayek F.A. (1945). The use of knowledge in society. Economica, 35(4): 519-530.

Hayek F.A. (1952). The sensory order. Chicago: Chicago University Press.

Hayek F.A. (1967). Studies in philosophy, politics and economics. Chicago: Chicago University Press.

Hayek F.A. (1988). The fatal conceit, the errors of socialism. Routledge.

Harsanyi J. (1964). Some social science implications of a new approach to game theory. Paper presented to the Conference on Conceptual and Experimental Analysis of Strategic Interaction and Conflict, Berkeley, California.

Hurwicz L. (1945). The theory of economic behavior. American Economic Review, 35(5): 909-925.

Hurwicz L. (1973). The design of mechanisms for resource allocation, American Economic Review, 63, 1-30.

Hurwicz L. (1975). On the existence of allocation systems whose manipulative nash equilibria are pareto-optimal.
Unpublished paper presented at 3rd World Congress of the Econometric Society, Toronto.

Janssen M. (2001). Rationalising focal points. Theory and Decision, 50, 119- 148.

Laughlin C.D. \& d'Aquili, E. (1974). Biogenetic structuralism. Columbia University Press.

Leeson, P.T., Coyne, C.J. \& Boettke, P.J. (2006). Converting social conflict: Focal points and the evolution of cooperation. Austrian Economic Review, 19, 137-147.

Lewontin R.C. (1961). Evolution and the theory of games, Journal of Theoretical Biology, 1, 382-403.

Menger, C. (1883). Untersuchungen ueber die Methode der Socialwissenschaften der politischen Oekonomie insbesondere. Dunker Humblot.

Maynard Smith, J. (1972). On evolution, Edinburgh University Press.

Merlo, A. \& Schotter A. (1999). A Surprise-Quiz View of Learning in Economic Experiments, Games and Economic Behavior, 28(1): 25-54.

Merlo, A. \& Schotter A. (2003). Learning by not doing: An experimental investigation of observational learning. Games and Economic Behavior, 42(1): 116-136.

Metha, J., Starmer C. \& Sugden R. (1990). Focal points in bargaining: An experimental Investigation. Economic Research Centre, University of East Anglia.

Metha, J., Starmer C. \& Sugden R. (1994). The Nature of Salience. An Experimental Investigation of Pure Coordination Games, American Economic Review, 74, 658-673.

Milgrom, P., North, D. \& Weingast, B. (1990). The role of institutions in the revival of trade: The law of merchant, private judges and champagne fairs. Economics and Politics, 2, 1-23.

Morgenstern, O. (1941). Professor Hicks on Value and Capital. Journal of Political Economy, 49, 361-393.

Morgenstern, O. (1963). On the accuracy of economic observations. ( $2^{\text {nd }}$ ed.). Princeton: Princeton University Press.

Morgenstern, O. (1972). Thirteen critical points in economic theory, Journal of Economic Literature 10, 1163-89.

Morgenstern, O. \& Schwödiauer , G. (1976). Competition and collusion in bilateral markets, Journal of Economics, $36,217-45$. 


\section{Ambrosino}

Neumann, J. Von \& Morgenstern, O. (1944). Theory of games and economic behaviour. Princeton: Princeton University Press.

Nozick, R. (1975). Anarchy, state, and Utopia. B. Blackwell.

Radner, R. \& Schotter, A. (1989). The sealed bid mechanism:

An experimental study. Journal of Economic Theory, 48, 179-220.

Rizzello, S., (1997). L’Economia della mente. Laterza.

Rizzello, S. \& Turvani, M. (2000). Institution meet mind: The way out of an impasse. Constitutional Political Economy, $11,165-180$.

Rizzello, S. \& Turvani, M. (2001). Subjective diversity and social learning: A cognitive perspective for understanding institutional behavior. Constitutional Political Economy, 13, $201-214$

Roth, A.E. (1985). Gauss-Theoretic Models of bargaining. Cambridge University Press.

Roth, A.E. \& Murnighan, J. (1982). The role of information in bargaining: An experimental study. Econometrica, L, 11231142.

Schelling, T.C. (1957). Bargaining, communication and limited war. Journal of Conflict Resolution, 1, 19-36.

Schelling, T.C. (1958). The strategy of conflict prospectus for a reorientation of game theory. Journal of Conflict Resolution, 2, 203-264.

Schelling, T.C. (1960). The Strategy of Conflict. Harvard University Press.

Schelling, T.C. (1961). Experimental games and bargaining theory. World Politics, 14(1): 47-68.

Schelling, T.C. (1978). Micromotives and macrobehavior. Norton and Company.

Schelling, T.C. (1984). Choice and consequence. Cambridge: Harvard University Press.

Schelling, T.C. (1993). Bargaining as binding oneself. This week's Citation Classic, 6, 18.

Schelling, T.C. (2005). Nobel prize interview. http://nobelprize.org/nobel_prizes/economics/laureates/200 5/schelling-telephone.html.

Schelling, T.C. (2006). Strategies of commitment and other essays. London: Harvard University Press.

Schotter, A. (1981). The Economic theory of social institutions. Cambridge: Cambridge University Press.

Schotter, A. (1992). Oskar Morgenstern's contribution to the theory of games. History of Political Economy, 4, 95-113.
Schotter, A. (2003). Decision making in the face of naive advice. American Economic Review Papers \& Proceedings, 93(2): 196-201.

Schotter, A. (2007). Interview to Angela Ambrosino, Rome, June 29.

Schotter, A. \& Schwodiauer, G. (1980). Economics and the theory of games: A survey. Journal of Economic Literature, 18, 479-527.

Schotter, A. \& Sopher, B. (2002). Social learning and coordination conventions in inter-generational games: An experimental study. Journal of Political Economy, 111(3): 498-529.

Shapley, L. \& Shubik, M. (1977). Trade using one commodity as a means of payment. Journal of Political Economy, 85, 937-968.

Shubik, M. (1959). Strategy and Markets Structure. New York: Wiley.

Shubik, M. (1971,1972). A Theory of money and financial institutions: Fiat money and non-cooperative equilibrium in a closed economy. International Journal of Game Theory, 1(1), 243-268.

Shubik, M. (1992). Game theory at Princeton, 1945-1955: A personal reminiscence.

Sudgen, R., Zamarrón, I. (2006). Finding the key: The riddle of focal points, Journal of Economic Psychology, 5, 609-621.

Sudgen, R. (1986). The Economics of Rights, Co-Operation and Welfare. Oxford: Blackwell.

Sudgen, R. (1995). A Theory of Focal Points, Economic Journal,105(430): 533-50.

Sudgen, R. \& Zamarrón, I. (2006). Finding the key: The riddle of focal points. Journal of Economic Psychology, 5, 609-621.

Telser, L. (1972). Competition, Collusion and Game Theory. Chicago: Aldine.

Young, H.P. (1991). An evolutionary model of bargaining. Journal of Economic Theory, 59, 145-168.

Young, H.P. (1993). Individual strategy and social structure: An evolutionary theory of institution. Princeton: Princeton University Press.

\section{ACKNOWLEDGMENT}

I am very grateful to Thomas Schelling for his helpful suggestions and comments. I am also 
International Journal of Management, Economics and Social Sciences

very grateful to Andrew Schotter for his kind and helpful suggestions. 